\section{EMBRYRIDDLE}

Aeronautical University

SCHOLARLY COMMONS
Journal of Aviation/Aerospace

Education \& Research

Volume 11

Number 3 JAAER Spring 2002

Article 9

Spring 2002

\title{
Using Applied Behavior to Complement Error Management in Crew Resource Management Education
}

William G. Rantz

Follow this and additional works at: https://commons.erau.edu/jaaer

\section{Scholarly Commons Citation}

Rantz, W. G. (2002). Using Applied Behavior to Complement Error Management in Crew Resource Management Education. Journal of Aviation/Aerospace Education \& Research, 11(3). https://doi.org/ 10.15394/jaaer.2002.1310

This Article is brought to you for free and open access by the Journals at Scholarly Commons. It has been accepted for inclusion in Journal of Aviation/Aerospace Education \& Research by an authorized administrator of Scholarly Commons. For more information, please contact commons@erau.edu. 


\title{
USING APPLIED BEHAVIOR ANALYSIS TO COMPLEMENT ERROR MANAGEMENT IN CREW RESOURCE MANAGEMENT EDUCATION
}

\author{
William G. Rantz
}

\begin{abstract}
This paper examines the science of applied behavior analysis and its potential integration into current research and practice of threat and error management for internal crew behaviors. Discussions provide insight into how an Antecedent-Behavior-Consequence ( $\mathrm{ABC}$ ) analysis of behavior can reveal to educators, the antecedents and consequences for at-risk crew behavior. This paper will redefine crew at-risk behaviors as anti-error behaviors that prevent internal error occurrence. This new perspective will complement and enhance the total threat-error process model. Finally the challenges and implications of using crew reinforcement to maintain anti-error behavior using modified line-oriented flight training (LOFT) will be discussed.
\end{abstract}

\section{What is Applied Behavior Analysis?}

Behavior analysis is not new to the field of psychology, however using behavior analysis within the field of aviation psychology, as evidenced in the literature, appears to be a novel approach whose time may be approaching. Some researchers (e.g., Rantz, Olson, \& Dickinson, 2001) are using new applications of behavior analysis to provide improvements to student landing performance in a flight training environment. "Despite the obvious relevance of this simple behavioral formulation to the understanding of factors such as motivation, the effects of incentives and deterrents and the effects of past experience on future behavior, virtually no systematic attention has been paid to it by aviation psychologists" (Fuller, 1994, p. 174). "Behavior analysis, far from representing an alternative to cognitive theory, may be regarded as complementary to it" (Fuller, 1994, p. 187). Behavior analysis is the scientific study of how environmental events cause changes in observable behaviors. While behavior analytic theory is regularly applied to private behavior (e.g., thoughts and feelings) when applicable, this paper will emphasize behavior analysis applied to the pilot's environment and his/her observable behavior.

Brethower (2000) provides a pragmatic overview of the behavior analysis of instruction in the following statement:

Behaviorists say that, at any moment in time, what a person brings to a specific situation is fixed. Whatever the person's intelligence is, whatever the person's personality is, whatever the person's goals and dreams are, they are what they are. What we can manipulate or change to improve performance is some part of the environment. Behavior analysts begin by asking this sort of question: 'What aspect of this environment can we change to improve this performance?' We aren't talking about broad-brush issues as changing inner-city neighborhoods, we are talking about specific changes such as altering the frequency of feedback or the rewards or the instruction. (p. 432)

Applied behavior analysis implicates the importance of scientifically collecting data regarding observable behavior because observed behavior itself is valuable (Miller, 1997). One aspect of behavior analysis used in Industrial/Organizational psychology is to teach individuals how to implement performance management and performance improvement techniques in the work place and evaluate their effectiveness (Daniels, 1989). Behavior analysis strategies typically employ objective measures of work performance, goal setting, performance feedback, and positive reinforcement. Evaluation strategies based on the on-going analysis of work performance over time allow individuals to make database management decisions about new and existing performance management systems. 
This notion of behavior observation, data collection, and the on-going analysis of crew performance corresponds to the work of the crew resource management (CRM) researchers at the University of Texas at Austin (UTAustin), led by Dr. Robert Helmreich. "Effective CRM programs are data driven, using information from surveys, observations of normal operations, and detailed analyses of errors, accidents, and incidents. Effective programs are both specific and practical. They deal with observable behaviors and eschew vague generalities and what is often called 'psychobabble'" (Helmreich, 2000, p. 2).

\section{Current Threat-Error Management}

Threat-error management awareness and practicing behaviors that detect errors are important components of human factors training. The practice of error management assumes the traditional elements of safety including, rules, safety training, and safety culture preexist in the appropriate governmental agency, employer organization, training department, and individual. These traditional and vitally important elements are used as layered safety shields to stop errors before becoming accidents (Reason, 1997). The current error management troika consists of avoidance of the error, trapping incipient errors before they are committed, and mitigating the consequences of errors that occur and are not trapped (Helmreich, Merritt, \& Wilhelm, 1999). Currently the UT-Austin model of threat and flight crew error management consists of four levels. These include; external threats (expected or unexpected events and risks including external errors), internal threats (crewbased errors), crew action (CRM behaviors or error detection and appropriate response behaviors), and outcomes (a safer flight, recovery to a safer flight, additional error, or a crew-based accident/incident).

There are five potential error types within each level of the model. The first is identified as intentional noncompliance errors (conscious violations of Standard Operating Procedures [SOPs]). The second is procedural errors (mistakes in procedures). The third is communication errors (errant internal or external verbal behavior). The forth is proficiency errors (deficient technical flight skills). The last error type is operational decision errors (operational decision parameters outside the SOPs and Federal Aviation Regulations [FARs]).

Helmreich, Klinect, and Wilhelm (1999) identified three general crew behaviors related to errors: trap the error, exacerbate the error, and fail to respond to the error. Failing to respond to an error can not constitute an observable crew behavior and perhaps results in exacerbating the error in the form of non-behavior. The definition of error is deviation from accuracy or correctness; a mistake, as in action or speech. This definition defaults to a reactive posture when managing errors that occur during the flight.

Therefore, it is suggested that to reduce errors within the flight environment and specifically the levels of internal threats and crew actions, the boundaries of focus be shifted forward, from the reactive behaviors of error management to the behaviors that cause the errors. Or better yet, identification of the behaviors, that if present, would avoid or minimize error development. It is believed that with training and reinforcement for appropriate, anti-error crew behavior, errors occurring within these two levels can be reduced significantly. How is it possible to improve safe crew behavior before an internal or crew produced error must be trapped or mitigated?

\section{Shift Focus Upstream of the Error}

It has been postulated in a reactive safety triangle that for every accident there will have been a larger number of incidents and for every incident there will have been even a larger number of errors, and for every error there will have been a vast number of at-risk behaviors (Geller, 1988). Many safety programs in business and industry focus on accident, incident, and errors when using measurement data to report changes in progress resulting from their safety initiatives. These programs fail to address the root cause of safety violations, that is, the at-risk behavior of the job performer. The key component to control of any safety program is the control of the unsafe behaviors that occur prior to the error, incident, or accident. Behavior-based safety interventions, founded on behavior analysis, have been used for the past 20 years to reduce accidents, incidents, and errors in the work environment by decreasing at-risk behaviors and increasing safety related behaviors (Grindle, Dickinson, \& Boettcher, 2000; SulzerAzaroff \& Austin, 2000).

The work of Seamester (Seamester, Prentiss, \& Edens, 1997) examines the verbal behavior of crews to determine which verbs are associated with improved CRM performance. This particular research attempts to identify more detailed observable CRM vocal behaviors (skills) for assessment and integration across operations. In the line operation safety audits (LOSA) conducted by the UTAustin team, many specific behaviors were identified as evidence of error avoidance as well as error exacerbation 
(Helmreich, Wilhelm, Klinect, \& Merritt, 2001). Both studies tend to emphasize the importance of particular observable CRM behaviors that should increase measurable performance output. The LOSA, among other things, is an objective checklist of observable crew behavior. The verbal behaviors that cause errors and avoid errors, identified by the LOSA, are the types of behaviors that must be pinpointed and used in the analysis of at-risk CRM behavior. The identification of these particular verbal behaviors will be the key to success. Verbal behavior can be defined as "behavior of an individual that has been reinforced through the mediation of another person." (Skinner, 1957, p.2). It is very likely that most anti-error behavior will be verbal behavior of which specific vocal behavior will be used in a specific environmental context. However, the analysis should also include non-vocal communicative behaviors, such as gesturing. Because the consequences of behavior influence whether or not behaviors occur again, this type of analysis should first identify the at-risk behavior of the consequences, which sustain it. Then the appropriate anti-error behavior (verbal or non-verbal) should be identified, and consequences altered so the anti-error behavior will occur (or be sustained), rather than the at-risk behavior. "Defining CRM in terms of specific behaviors has been a trend toward proceduralization of CRM, requiring interpersonal behaviors and communications as part of technical maneuvers. The positive side to this is clear guidance for crews as to expected behaviors and, concurrently, the ability to assess and reinforce their practice" (Helmreich et al., 2001, p. 18).

\section{The ABCs of CRM Flight Deck Behaviors}

One key component of behavior analysis is the use of an $A B C$ analysis (Daniels, 1989; Krause, 1997). This analysis consists of observing the crew's behavior within the environment and identifying the particular behaviors of interest. "An $\mathrm{ABC}$ analysis entails identifying relevant antecedents and consequences for behavior, where antecedents are stimuli or conditions that precede behavior and set the stage for or prompt it to occur; and consequences are stimuli or conditions that follow a behavior and change the probability that it will recur" (Olson \& Austin, 2001, p. 21). Once the particular causal error behaviors are identified, constructing an $A B C$ analysis using a three-term contingency diagram will reveal which consequences within the environment are reinforcing the error behavior. The analysis will also identify the critical antecedents that should prompt the appropriate behavior, reducing "failure to respond" errors.

Thus the $\mathrm{ABC}$ analysis, when complete, identifies the (a) conditions under which the behavior should occur, (b) the specific, observable anti-error behavior that should occur, and (c) the consequences that result when the antierror behavior occurs.
The well-known performance management consultant, Aubrey Daniels said, "Every behavior has a consequence. In fact, behavior can be viewed as a function of its consequences. That is, consequences do not simply influence what someone does; they control it. In order to understand why people do what they do, instead of asking, 'Why did they do that?' ask, 'What happens to them when they do that'" (Daniels 1989, p. 24). The key to finding a good reinforcer is to look at what happens to the person immediately after the behavior. Strong reinforcers are positive (P), immediate (I), and certain (C) and when presented after a behavior, maintain the current frequency of the behavior if it is at strength or increases the future frequency of the behavior. However, many consequences in our environment are negative $(\mathrm{N})$, delayed into the future (F), and uncertain (U) (Daniels, 1989). Negative consequences may punish an appropriate behavior, delayed positive consequences may reinforce an inappropriate behavior that occurs in between the appropriate behavior and the delayed consequence, and uncertain positive consequences may not occur frequently enough to influence an appropriate behavior. Additionally, delayed and 
improbable consequences are often hard to identify.

It has been mentioned that for the sake of increasing operational efficiency, some violations such as intentional non-compliance errors are made. Sixty two percent of the total errors cited by the UT-Austin Team LOSA observations revealed the crew's disregard in reading many checklist items required during operation. These were labeled as intentional non-compliance errors (Helmreich et al., 2001). The error behavior was engaging in activity other than the required reading of the checklist response of the moment. An ABC analysis should reveal other consequences present in the environment, which may be reinforcing behavior other than reading the checklist or may be punishing checklist reading behavior.

Undesired Behavior: Crew not reading the checklist Antecedents

Consequences

\begin{tabular}{|c|c|}
\hline Time to do other things & Less of a work load (P), (I), (C) \\
\hline Other environmental stimuli distract attention & Gets to attend other priority items (P), (I), (C) \\
\hline Seeing others not read checklist & Might get reprimanded (N), (F), (U) \\
\hline Doesn't believe an incident will occur & Might have an incident (N), (F), (U) \\
\hline
\end{tabular}

Desired Behavior: Crew reads from checklist Antecedents

\begin{tabular}{|c|c|}
\hline Ahreat of disciplinary action & Might get praise (P), (I), (U) \\
\hline Seeing others read checklist & Less time to attend other distracters (N), (I), (C) \\
\hline Just had a near miss & Incident is unlikely over checklist items (P), (I), (U) \\
\hline Just came from training & Must locate and find place on checklist (N), (I), (C) \\
\hline
\end{tabular}

Based on the $\mathrm{ABC}$ analysis, It would be prudent to reduce or eliminate error behavior or distractions resulting in not reading the checklist by reducing or eliminating the reinforcers responsible for that behavior. In turn, it would also be wise to increase the reinforcers for the anti-error behavior of reading the checklist. Using our example of crews not using the checklist we can analyze the consequences of that particular at-risk behavior. It becomes evident that the crew has some powerful positive, immediate, and certain reinforcers present that support behaviors other than reading the checklist and the negative consequences are too uncertain and far in the future to influence the current behavior. To establish the new antierror behavior of reading the checklist, new environmental reinforcers must be made contingent upon it. Using the $\mathrm{ABC}$ analysis can reveal the need to include more positive, immediate, and certain reinforcers that are contingent upon the desired checklist reading behavior. The consequences, in turn, will increase the future frequency of that particular reading behavior. Detractions and interruptions of checklist reading behavior are an accepted fact of the operation. Airlines may wish to adopt specific vocal responses provided by the crew, which will establish an opening, "Ready for after takeoff check?" and a closing, "After takeoff check complete." to each checklist segment. The contingent consequence to the final vocal response, closing segment could be a simple, "Good job, thank you". This would fulfil the (P), (I), (C), requirement of a good consequence. Therefore, interrupted checklist reading behavior should be followed by a continuation of the segment and the closing consequence excluding any higher threat items. A further example of $\mathrm{ABC}$ analysis requires $C R M$ vocal behavior while encountering a potential threat in the instrument environment. 


\section{ABC Analysis of Anti-error CRM Verbal Behavior}

\begin{tabular}{|c|c|c|}
\hline Antecedent & Behavior & Consequence \\
\hline Threat increase & Anti-error Behavior & Threat decrease \\
\hline $\begin{array}{l}\text { ATC: Due to weather, hold at the } \\
\text { AZO VOR at } 8,000 \text {. Expect } \\
\text { further clearance } 1250 Z \text {. Time } \\
\text { now } 1210 Z \text {. }\end{array}$ & $\begin{array}{l}\text { Lets discuss our situation with } \\
\text { regard to weather movement, } \\
\text { possible future delays, and our } \\
\text { current and projected fuel status } \\
\text { at EFC. }\end{array}$ & $\begin{array}{l}\text { Situational awareness is piqued. } \\
\text { Alternative action envisioned and } \\
\text { contingencies prepared. Praise } \\
\text { from Captain. }\end{array}$ \\
\hline
\end{tabular}

This $\mathrm{ABC}$ analysis exhibits a potential threat increase in the flight environment in the form of holding instructions from ATC, which the crew recognizes. The crew's response is to use one particular anti-error vocal behavior to initiate a situational assessment. The results are multiple consequences for this behavior in the form of reducing the threat (P), (I), (C); agreement on the current state and future course of action (P), (I), (C); and the Captain's acknowledgement of good crew performance $(\mathrm{P})$, (I), (C). If pilots were trained in this process to understand the importance of positive immediate and certain consequences for appropriate behaviors many more antierror behaviors would occur on the flight deck. The process to establish new contingencies of behavior on the flight deck requires training, reinforcers, and feedback within the educational environment and in line operations.

\section{Implications for Anti-error Reinforcement in CRM\& LOFT Education}

"Key personnel responsible for training and evaluation of performance need special training in the concepts and assessment of threat and error management. It is essential that error management be evaluated and reinforced not only in training but also in line operations. The major change here is in formally recognizing that error, in itself, is part of system operations and that effective error management can represent effective crew performance" (Helmreich et al., 2001, p. 21).

There are several essential points required to maximize the educational resources needed to implement a behaviorbased threat-error model of training. The first point is learning the principles of $A B C$ analysis and understanding what happens to people when they behave in a particular way. This can be conducted in a classroom setting using many everyday examples and role playing techniques. The second point is to train this new behavior to fluency.
Fluency is the term used for improving the accuracy and rate of behaviors. Training to fluency is no stranger to skills training in the aviation industry. This type of training is usually a function of technical flight skills training and yet is rarely used for CRM skills training. The same time used for traditional, full mission line oriented flight training (LOFT) can be modified to adopt fluency training that shapes anti-error verbal behaviors in simulated environments. This type of training would shift the focus from using full mission LOFT scenarios to developing and evaluating CRM skills in a more frequent, shorter, and varied LOFT vignettes. This shift of training exposure would provide the crew with higher rates of practice and feedback with regard to particular modules of anti-error behaviors and in particular the contingent reinforcers and performance outcomes of those behaviors. Once the crew dem nstrated a variety of CRM skills, a full mission nonjeopardy LOFT would be used to conclude the training. Brethower and Smalley (1998) describe a performancebased instructional method that uses a systems approach to training. This system develops the contingencies of behavior, using a real-world approach, by providing guided observations, guided practice and demonstration of mastery. A new training system, based on this model, will shift the focus upstream, from the errors to the anti-error behaviors. This new proposed performance-based teaching system will allow the flight crew to first experience knowledge and role-play through guided observations from the classroom, secondly to experience guided practice during the LOFT vignettes and finally to demonstrate mastery in a more traditional full mission LOFT. Ensuring the success and maintenance of the anti-error behaviors is the final point. This may require a self-reporting, or intercrew reporting observation and non-jeopardy feedback system of CRM performance. A simple system was used with a roofing crew, which showed immediate and lasting 
changes in safety performance (Austin, Kessler, Riccobono, \& Bailey, 1996). This type of system would provide immediate, positive and certain reinforcers to the flight crew with regard to their past performance and reinforce the error avoidance behaviors shaped during periodic recurrent training. A superb project management technique that approaches the high level of crew behavior observation and feedback is the Proficiency Assessment and Training System (PATS) being used by Ansett Australia. PATS uses an integration of simulator and line assessments and safety related feedback data, which determine training design needs. This intégrated check and training system uses crew behavior and performance outcome measures during training and line checks to continually evaluate the effectiveness of the company's training program and pinpoint crew performances that require additional training (Henderson, 2000). To complement a PATS process, using behavior analysis principles, would include a direct feedback link not just to the training department but to the crew during line checks. This proposed closed loop observation-feedback system would build the positive, immediate, and certain reinforcers required to establish contingencies of appropriate crew behaviors and performance. This could also include an on-going, nonjeopardy reward program that recognizes the "good" performance of crewmembers.

There are seven essential elements that are required to integrate a behavioral approach into flight operations. They consist of the following:

1. Assess current LOSA data to pinpoint verbal and nonverbal at-risk behaviors.

2. Identification of consequences supporting at-risk behavior.

3. Replace observed at-risk behaviors with various antierror behaviors.

4. Modify the standard operating procedures to include appropriate consequences, which will sustain the various anti-error behaviors.

5. Train crews in $A B C$ analysis and inter-crew observations.
6. Arrange for the crew to practice, through role-play, various anti-error behavior and consequence contingencies in class using shortened LOFT vignettes.

7. Establish an objective inter-crew observation system which provides anonymous, non-punitive, and timely feedback of CRM behaviors to the crew and the training department.

\section{Summary}

It would be incorrect to imply that using behavior analysis and threat-error management affords pilots the opportunity to believe they are error-free. This dangerously assumes an "internalized" error-free attitude that a person carries with them from one environment to another. External environmental procedures, policies, technologies, training, feedback, and behavioral contingencies are the key elements to establish an error-reducing environment in which the highly trained human interacts. Line operational safety audits have shown that the current system of training does not eliminate crew errors on the flight deck. Many have said that errors can not be totally eliminated because errors are simply a function of having a human within the system. If this is so then we as scientists, psychologists, or educators are obligated to examine all behavioral principles that can provide evidence of performance change and use those principles as a means to complement error reduction methods already in existence. Behavior analysis, with its scientifically validated behavioral principles, has great potential to improve and balance the training initiatives of the threat-error process model in CRM. Shifting the intervention focus upstream from the error and targeting atrisk behavior gives the educator a proactive direction. Identifying the antecedents and arranging behaviorstrengthening consequences for anti-error behavior are the key for developing and maintaining anti-error behaviors. A vigorous, performance-based crew resource systems program that identifies, shapes and reinforces the appropriate anti-error behavior contingencies will provide that ounce of prevention thereby avoiding that pound of cure. $\mathrm{D}$

William G. Rantz is an Assistant Professor at the College of Aviation - Western Michigan University in Kalamazoo, Michigan. He graduated with an M.A. in Career and Technical Education and is currently finishing a second masters degree in Industria//Organizational Psychology and a Ph.D. in Behavior Analysis specializing in aviation psychology and safety education. Professor Rantz holds an Airline Transport Pilot Certificate and a Flight Instructor Certificate. 


\section{REFERENCES}

Austin, J., Kessler, M., Riccobono, J., \& Bailey, J. (1996). Using feedback and reinforcement to improve the performance and safety of a roofing crew. Journal of Organizational Behovior Management, 16 (2), 49-75.

Brethower, D. M. (2000). Organizational behavior management and instructional systems. In J. Austin \& J. E. Carr (Eds.), Handbook of applied behavior analysis (pp. 423-447). Reno, NV: Context Press.

Brethower, D. M., \& Smalley, K. (1998). Performance-based instruction: Linking training to business results. San Francisco, CA: Jossey-Bass / Pfeiffer.

Daniels, A. C. (1989). Performance management: Improving quality and productivity through positive reinforcement. Tucker, GA: Performance Management Publications.

Fuller, R. (1994). Behavior analysis and aviation safety. In N. Johnston, N. McDonald, \& R. Fuller (Eds.), Aviation psychology in practice (pp. 173-189). Burlington, VT: Ashgate Publishing.

Geller, E. S. (1988). Managing occupational safety. Blacksburg, VA: Make-A-Difference, Inc.

Grindle, A. C., Dickinson, A. M., \& Boettcher, W. (2000). Behavioral safety research in manufacturing settings: A review of the literature. Journal of Organizational Behavior Management, 20, 29-68.

Helmreich, R. L. (2000). Threat and error in aviation and medicine: Similar and different. Proceedings from the Fifth Australian Aviation Psychology Association Symposium. Manly, AU. Australian Aviation Psychology Association.

Helmreich, R. L., Klinect, J. R., \& Wilhelm, J. A. (1999). Models of threat, error, and CRM in flight operations. Proceedings of the Tenth International Symposium on Aviation Psychology (pp. 677-682). Columbus, OH: The Ohio State University.

Helmreich, R. L., Merritt, A. C., \& Wilhelm, J. (1999). The evolution of crew resource management training in commercial aviation. International Journal of Aviation Psychology, 9, 19-32.

Helmreich, R. L., Wilhelm, J. A., Klinect, J. R., \& Merritt, A. C. (2001). Culture, error, and crew resource management. In E. Salas, C.A. Bowers, E. Edens (Eds.), Improving teamwork in organizations (pp. 305-331). Hillsdale, NJ: Erlbaum.

Henderson, S. (2000). Using assessment data: Bridging the gap between checking and training. Proceedings from the Fifth Australian Aviation Psychology Association Symposium. Manly, AU. Australian Aviation Psychology Association.

Krause, T. R. (1997). The behavior-based safety process. New York: Van Nostrand Reinhold.

Miller, K. L. (1997). Principles of everyday behavior analysis. Pacific Grove, CA: Brooks/Cole Publishing.

Olson, R, \& Austin, J. (2001, November). ABCs for lone workers: A behavior-based study of bus drivers. Professional Safety, pp. 20-25.

Rantz, W. G., Olson, R, \& Dickinson, A. M. (in press). Complementing the traditional hierarchy of aviation safety controls with a behavior-based safety system: Preliminary findings from the College of Aviation at Western Michigan University. Proceedings of the Tenth International Symposium of Aviation Psychology, Columbus, OH: The Ohio State University.

Reason, J. (1997). Managing the risks of organisational accidents. Aldershot, UK: Ashgate.

Seamster, T. L., Prentiss, F. A., \& Edens, E. S. (1997). Methods for the analysis of CRM skills. Ninth International Symposium on Aviation Psychology. pp. 260-266. Columbus, OH: The Ohio State University.

Skinner, B. F. (1957). Verbal behavior. Copley Publishing Group. Acton, MS.

Sulzer-Azaroff, B., \& Austin, J. (2000, July). Does BBS work? Behavior-based safety and injury reduction: A survey of the evidence. Professional Safety, pp. 19-24. 
Journal of Aviation/Aerospace Education \& Research, Vol. 11, No. 3 [2002], Art. 9 